Article

\title{
Decreasing Wellbeing and Increasing Use of Negative Coping Strategies: The Effect of the COVID-19 Pandemic on the UK Health and Social Care Workforce
}

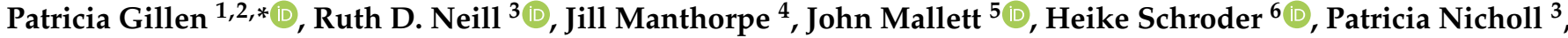

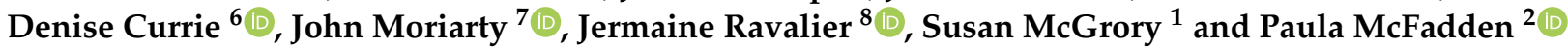

Citation: Gillen, P.; Neill, R.D.; Manthorpe, J.; Mallett, J.; Schroder, H.; Nicholl, P.; Currie, D.; Moriarty, J.; Ravalier, J.; McGrory, S.; et al. Decreasing Wellbeing and Increasing Use of Negative Coping Strategies: The Effect of the COVID-19

Pandemic on the UK Health and Social Care Workforce. Epidemiologia 2022, 3, 26-39. https://doi.org/ 10.3390/epidemiologia3010003

Academic Editor: Giada Minelli

Received: 12 November 2021

Accepted: 14 January 2022

Published: 18 January 2022

Publisher's Note: MDPI stays neutral with regard to jurisdictional claims in published maps and institutional affiliations.

Copyright: (C) 2022 by the authors. Licensee MDPI, Basel, Switzerland. This article is an open access article distributed under the terms and conditions of the Creative Commons Attribution (CC BY) license (https:// creativecommons.org/licenses/by/ $4.0 /$ )
1 School of Nursing, Jordanstown Campus, Ulster University, Shore Road, Newtownabbey BT37 0QB, UK; s.mcgrory@ulster.ac.uk

2 Southern Health and Social Care Trust, 10 Moyallen Road, Gilford BT63 5JX, UK; p.mcfadden@ulster.ac.uk

3 School of Applied Social Policy Sciences, Magee Campus, Ulster University, Londonderry BT48 7JL, UK; r.neill@ulster.ac.uk (R.D.N.); p.nicholl2@ulster.ac.uk (P.N.)

4 NIHR Health and Social Care Workforce Research Unit, King's College London, 22 Kingsway, London WC2B 6LE, UK; jill.manthorpe@kcl.ac.uk

5 School of Psychology, Coleraine Campus, Ulster University, Cromore Road, Coleraine BT52 1SA, UK; j.mallett@ulster.ac.uk

6 Queen's Management School, Queen's University Belfast, Riddel Hall, 185 Stranmillis Road, Belfast BT9 5EE, UK; h.schroder@qub.ac.uk (H.S.); d.currie@qub.ac.uk (D.C.)

7 School of Social Sciences, Education and Social Work, Queen's University Belfast, 69-71 University Street, Belfast BT7 1HL, UK; j.moriarty@qub.ac.uk

8 School of Science, Bath Spa University, Newton Park, Newton St. Loe, Bath BA2 9BN, UK; j.ravalier@bathspa.ac.uk

* Correspondence: p.gillen@ulster.ac.uk

Abstract: Many health and social care (HSC) professionals have faced overwhelming pressures throughout the COVID-19 pandemic. As the current situation is constantly changing, and some restrictions across the UK countries such as social distancing and mask wearing in this period (May-July 2021) began to ease, it is important to examine how this workforce has been affected and how employers can help rebuild their services. The aim of this study was to compare cross-sectional data collected from the HSC workforce in the UK at three time points during the COVID-19 pandemic: Phase 1 (May-July 2020), Phase 2 (November 2020-January 2021) and Phase 3 (May-July 2021). Respondents surveyed across the UK (England, Wales, Scotland, Northern Ireland) consisted of nurses, midwives, allied health professionals, social care workers and social workers. Wellbeing and work-related quality of life significantly declined from Phase 1 to $3(p<0.001)$; however, no significant difference occurred between Phases 2 and $3(p>0.05)$. Respondents increasingly used negative coping strategies between Phase 1 (May-July 2020) and Phase 3 (May-July 2021), suggesting that the HSC workforce has been negatively impacted by the pandemic. These results have the potential to inform HSC employers' policies, practices, and interventions as the workforce continues to respond to the COVID-19 virus and its legacy.

Keywords: COVID-19; healthcare workforce; social care workforce; social work; United Kingdom; coping; wellbeing; quality of working life; survey

\section{Introduction}

Declared a pandemic in March 2020 [1], the novel Coronavirus (COVID-19) outbreak spread rapidly worldwide, changing how individuals lived and worked, with a severe impact on health, education, politics, the environment, and the economy [2-4]. According to the World Health Organisation dashboard [5], over 5.4 million deaths and 281.8 million cases have occurred worldwide so far, with 148,021 deaths and 12.3 million cases in the United Kingdom (UK) as of 4 January 2022. The pandemic initially introduced severe 
restrictions on daily activity and travel. Guidance on social distancing, mask wearing, working from home if possible and the importance of good hygiene practices, such as handwashing were highlighted in public health campaigns globally [6-10]. These changes affected working conditions for millions, particularly those working in the health and social care (HSC) sector, many of whom also experienced new pressures at work.

Accounting for over 3 million people across the UK [11], health and social care (HSC) workers provide essential long term and short term care to individuals and families across a range of populations (adults, children, learning disability, mental health, physical disability, older people's care, and so on) and settings. How direct care and support are provided has altered much during the COVID-19 pandemic. Pre-pandemic, the HSC workforce was already viewed as a high risk group for mental health problems, severe stress, lower wellbeing and higher burnout as budget cuts, lack of resources and policy reforms placed services under substantial pressures taking a detrimental toll on HSC staff and employers [12-15]. The current HSC workforce faced long-lasting consequences due to the heavy responsibility placed on these professionals during the pandemic [16-19]. Even when restrictions ease in many countries, with removal of the full social distancing and maskwearing measures in most environments, the burden on this workforce remains. Whilst considerable measures such as COVID-19 and flu vaccination programmes, promotion of maskwearing indoors and good hygiene have been widely promulgated and successful across the UK [20-22], the virus spread is still present, particularly as the seasons change and new virus variants circulate.

Emerging research during the COVID-19 crisis documented the negative toll of working in the HSC sector, with adverse consequences in terms of coping strategies adopted, lower work-related quality of life and wellbeing for HSC employees. The pandemic changed how care was delivered, with staff often working under greater pressure, straining their current coping strategies as job demands and stress increase [12,16,23,24]. Isolation, social restrictions, changes in care and operational pathways, communication problems between employees, employers and providers, longer waiting lists, and new working practices have been further exacerbated by the stress of the pandemic [12,25-27]. Changes in working conditions and lifestyles have led to burnout amongst some, with higher job demands, fewer available resources and staff turnover/shortages affecting mental wellbeing and quality of working life $[16,17,24,25,28-31]$. This evidence suggests a need for continued exploration of burnout, coping strategies, mental wellbeing, and work-related quality of life in the HSC sector over the course of the pandemic and beyond.

This current study aimed to compare cross-sectional data collected from nurses, midwives, AHPs, social care workers and social workers in the UK at three different time points (Phase 1: May-July 2020; Phase 2: Nov 2020-Jan 2021; Phase 3: May-July 2021) during the COVID-19 pandemic. It specifically examined self-reported coping strategies, mental wellbeing, burnout, and quality of working life. This paper aims to provide an insight into the wellbeing of nurses, midwives, AHPs, social care workers and social workers, and explores the importance and relevance of certain variables between all three different phases of the COVID-19 pandemic. Examining the difference in wellbeing and work-related quality of life over the course of the pandemic is crucial in helping to identify any relevant supports for this workforce. The results of Phase 3 of this study will be used to expand on recommendations from earlier phases that could be used to inform policies and procedures for HSC employers to help counteract the adverse long-term effects the pandemic on mental wellbeing and work-related quality of life. Other papers linked to the wider study have explored the findings of the earlier phases [32,33], social care and social workers [34] and the 'clapping for carers' initiative [35].

\section{Materials and Methods}

\subsection{Study Design and Sample}

This study forms a part of a continuous research programme entitled 'Health and social care workers' quality of working life and coping while working during the COVID-19 
pandemic'. The overall research project focuses on mental wellbeing, quality of working life, burnout and coping strategies in nurses, midwives, allied health professionals (AHPS), social care workers and social workers from across the UK who are employed in a range of settings such as the community, day services, care homes and hospitals. The findings from this research aim to provide evidence-based recommendations for supporting the HSC workforce not just during the COVID-19 crisis, but also during business-as-usual times. The wider study uses a cross-sectional design, and the data for the current study presented here were collected at three time points: Phase 1: 7 May to 3 July 2020, Phase 2: 17 November 2020 to 1 February 2021 and Phase 3: 10 May to 2 July 2021. The research used an online survey with previously validated measures that also contained a small number of qualitative questions to further understand the self-reported experience of HSC professionals aged from 16 years upwards. The survey draws on a convenience sample of those who choose to participate voluntarily by accessing the survey through social media platforms such as Facebook and Twitter, professional associations, workplace unions, professional communications, employers, and regulatory bodies. An electronic link and QR code to the Participant Information Sheets, consent and survey were provided through these platforms to try and reach a wider population of health and social care workers across the UK. Participants could withdraw from the study at any time by not completing the survey. Clicking on the arrow to proceed after the Participant Information Sheet and completion of the survey indicated consent. Study eligibility was based on respondents self-reporting their occupation and country of work. For all phases, data were collected anonymously through the Qualtrics platform which hosted the anonymous online survey tool. Phase 1 received a total of 3290 responses, Phase 2 received 3499 responses and Phase 3 received 2721 responses. Demographic and work-related characteristics of the sample by study phase are presented in Table 1 .

Table 1. Demographics and work-related characteristics of sample (Phase 1: $n=2546$; Phase 2: $n=2718$; Phase 3: $n=2212$ ).

\begin{tabular}{|c|c|c|c|}
\hline Variable & $\begin{array}{c}\text { Phase } 1 \\
\text { (7 May-3 July 2020) }\end{array}$ & $\begin{array}{c}\text { Phase } 2 \\
\text { (17 November 2020-1 February 2021) }\end{array}$ & $\begin{array}{c}\text { Phase } 3 \\
\text { (10 May-2 July 2021) }\end{array}$ \\
\hline \multicolumn{4}{|l|}{ Sex } \\
\hline Female & $2221(87.2 \%)$ & $2398(88.2 \%)$ & $1952(88.2 \%)$ \\
\hline Male & $325(12.8 \%)$ & $320(11.8 \%)$ & $260(11.8 \%)$ \\
\hline \multicolumn{4}{|l|}{ Age } \\
\hline $16-29$ & $303(11.9 \%)$ & 304 (11.2\%) & $185(8.4 \%)$ \\
\hline $30-39$ & $539(21.2 \%)$ & $628(23.1 \%)$ & $412(18.6 \%)$ \\
\hline $40-49$ & $753(29.6 \%)$ & $714(26.3 \%)$ & $598(27.1 \%)$ \\
\hline $50-59$ & $755(29.7 \%)$ & $811(29.8 \%)$ & $783(35.4 \%)$ \\
\hline $60+$ & $195(7.7 \%)$ & $261(9.6 \%)$ & $232(10.5 \%)$ \\
\hline \multicolumn{4}{|l|}{ Ethnic background } \\
\hline White & $2395(94.2 \%)$ & $2605(96.1 \%)$ & $2129(96.4 \%)$ \\
\hline Black & $74(2.9 \%)$ & $40(1.5 \%)$ & $30(1.4 \%)$ \\
\hline Asian & $29(1.1 \%)$ & $26(1.0 \%)$ & $19(0.9 \%)$ \\
\hline Mixed & $44(1.7 \%)$ & $41(1.5 \%)$ & $31(1.4 \%)$ \\
\hline \multicolumn{4}{|l|}{ Country of work } \\
\hline England & $905(35.5 \%)$ & $633(23.3 \%)$ & $434(19.5 \%)$ \\
\hline Scotland & $107(4.2 \%)$ & $350(12.9 \%)$ & $611(27.6 \%)$ \\
\hline Wales & $146(5.7 \%)$ & $843(31.0 \%)$ & $266(12.0 \%)$ \\
\hline Northern Ireland & $1388(54.5 \%)$ & $892(32.8 \%)$ & $901(40.7 \%)$ \\
\hline \multicolumn{4}{|l|}{ Occupational group } \\
\hline Nursing & $142(5.6 \%)$ & $283(10.4 \%)$ & $459(20.8 \%)$ \\
\hline Midwifery & $139(5.5 \%)$ & $57(2.1 \%)$ & $136(6.1 \%)$ \\
\hline Allied Health Professionals & $311(12.2 \%)$ & $490(18.0 \%)$ & $312(14.1 \%)$ \\
\hline Social Care Workers & $919(36.1 \%)$ & $946(34.8 \%)$ & $674(30.5 \%)$ \\
\hline Social Workers & $1035(40.7 \%)$ & $942(34.7 \%)$ & $631(28.5 \%)$ \\
\hline \multicolumn{4}{|c|}{ Number of years of work experience } \\
\hline Less than 2 years & $211(8.3 \%)$ & $183(6.7 \%)$ & $116(5.2 \%)$ \\
\hline $2-5$ years & $373(14.7 \%)$ & $373(13.7 \%)$ & $282(12.8 \%)$ \\
\hline $6-10$ years & $407(16.0 \%)$ & $449(16.5 \%)$ & $303(13.7 \%)$ \\
\hline $11-20$ years & $688(27.0 \%)$ & $824(30.3 \%)$ & $596(27.0 \%)$ \\
\hline $21-30$ years & $572(22.5 \%)$ & $548(20.2 \%)$ & $488(22.1 \%)$ \\
\hline More than 30 years & $295(11.6 \%)$ & $340(12.5 \%)$ & $425(19.2 \%)$ \\
\hline
\end{tabular}


Table 1. Cont.

\begin{tabular}{|c|c|c|c|}
\hline Variable & $\begin{array}{c}\text { Phase } 1 \\
\text { (7 May-3 July 2020) }\end{array}$ & $\begin{array}{c}\text { Phase } 2 \\
\text { (17 November 2020-1 February 2021) }\end{array}$ & $\begin{array}{c}\text { Phase } 3 \\
\text { (10 May-2 July 2021) }\end{array}$ \\
\hline \multicolumn{4}{|l|}{ Place of Work } \\
\hline Hospital & $250(9.8 \%)$ & $304(11.2 \%)$ & $458(20.7 \%)$ \\
\hline Community & $1446(56.9 \%)$ & $1277(47.1 \%)$ & $989(44.8 \%)$ \\
\hline General Practice based & $12(0.5 \%)$ & $45(1.7 \%)$ & $31(1.4 \%)$ \\
\hline Care Home & $303(11.9 \%)$ & $267(9.9 \%)$ & $200(9.1 \%)$ \\
\hline Day Care & $47(1.8 \%)$ & $92(3.4 \%)$ & $61(2.8 \%)$ \\
\hline Other & $484(19.0 \%)$ & $725(26.8 \%)$ & $469(21.2 \%)$ \\
\hline \multicolumn{4}{|l|}{ Main area of practice } \\
\hline Children & $531(20.9 \%)$ & $714(26.3 \%)$ & $389(17.6 \%)$ \\
\hline Midwifery & $138(5.4 \%)$ & $55(2.0 \%)$ & $137(6.2 \%)$ \\
\hline Adults & $485(19.1 \%)$ & $594(21.9 \%)$ & $552(25.0 \%)$ \\
\hline Physical Disability & $50(2.0 \%)$ & $51(1.9 \%)$ & $35(1.6 \%)$ \\
\hline Learning Disability & $285(11.2 \%)$ & $295(10.9 \%)$ & $233(10.5 \%)$ \\
\hline Older People & $602(23.7 \%)$ & $533(19.6 \%)$ & $470(21.2 \%)$ \\
\hline Mental Health & $216(8.5 \%)$ & $274(10.1 \%)$ & $219(9.9 \%)$ \\
\hline Other & $238(9.4 \%)$ & $202(7.4 \%)$ & $177(8.0 \%)$ \\
\hline \multicolumn{4}{|l|}{ Disability status } \\
\hline Yes & $222(8.7 \%)$ & $271(87.7 \%)$ & $285(12.9 \%)$ \\
\hline No & $2268(89.1 \%)$ & $2384(87.7 \%)$ & $1865(84.4 \%)$ \\
\hline Unsure & $56(2.2 \%)$ & $62(2.3 \%)$ & $61(2.8 \%)$ \\
\hline \multicolumn{4}{|l|}{ Redeployment } \\
\hline Yes & $361(14.2 \%)$ & $319(11.7 \%)$ & $299(13.5 \%)$ \\
\hline No & $2185(85.8 \%)$ & $2399(88.3 \%)$ & $1913(86.5 \%)$ \\
\hline
\end{tabular}

Note: Presented are column percentages, which are valid percentages to account for missing data.

\subsection{Ethical Considerations}

Ethical approval was obtained from the Research Ethics Filter Committee of the School of Nursing at Ulster university (Ref No: 2020/5/3.1, 23 April 2020, Ulster University, IRAS Ref No. 20/0073) phases of the study and Trust Governance approval (for Northern Ireland only) was gained from Health and Social Care Trusts from Phase 2 onwards. This allowed the link to the questionnaire in Phase 2 and Phase 3 to be shared with HSC staff in Northern Ireland via their Trust work emails. While respondents were volunteering to undertake the anonymous survey, it was thought possible that during completion that they may become distressed. Therefore, at both the bottom of the Participant Information Sheet and the end of the survey, respondents were provided with information about whom to contact if they needed support. Permission for the use of the scales used in the questionnaire was provided by original authors, and consent and confidentiality were addressed in Participant Information Sheets provided at the start of the survey.

\subsection{Measures}

\subsubsection{Demographics and Work-Related Characteristics}

Respondents were asked about their demographic and work-related characteristics. The variables that were consistent across all three time points of the wider study and relevant to the analysis in this present paper are sex, age, country of work, ethnicity, occupation, years of work experience, disability status and redeployment status during the pandemic.

\subsubsection{Mental Wellbeing}

Mental wellbeing was assessed by the 7 item, short version of the Warwick-Edinburg Mental Wellbeing Scale (SWEMWS) which has statements about thoughts and feelings [36]. The scale is scored by summing the scores for each item, which range from 1 (None of the time) to 5 (All of the time), then the total raw scores are transformed by the SWEMWS conversion table into metric scores. Higher scores indicate positive wellbeing with scores ranging from 7 to 35 . The scale has shown good psychometric properties within the UK general population [37] and Danish adult populations [38]; in the present study, internal consistency was good in the final sample $(\alpha=0.87)$. 


\subsubsection{Work-Related Quality of Life}

Overall, work-related quality of life was assessed with the 23-item Work Related Quality of Life (WRQoL) scale [39] which reports employees' perceived quality of life measured through 6 sub domains (job career satisfaction, stress at work, working conditions, control at work, general wellbeing, and home-work interface). Respondents were asked to rate the items using a five-point Likert scale ranging from 1 (Strongly disagree) to 5 (Strongly agree) to indicate their attitudes to the factors that influence their quality of working life with higher scores indicating better work-related quality of life. The scale has previously shown good psychometric properties $[39,40]$ and in this present research internal consistency was good in the final sample $(\alpha=0.88)$.

\subsubsection{Burnout}

Burnout was assessed using the 19-item Copenhagen Burnout Inventory (CBI) [41], which measured three different areas of burnout: personal, work-related, and client-related. Twelve items were rated on a five-point Likert scale ranging from 0 to 100 (never/almost never to always) while seven items offered response categories ranging from a very low degree to very high degree. Scale scores were computed as the average (mean) scores across all relevant items. For each area of burnout, a mean score was calculated, with higher scores indicating a higher level of possible burnout. In the current study, the burnout scores in each area were categorised into low, moderate, high, and severe burnout using the cut-off scores as frequently cited in the literature [42]. The scale has shown good psychometric properties, for example, personal $(\alpha=0.89)$, work-related $(\alpha=0.90)$ and client-related $(\alpha=0.90)$ burnout [43] and, in this present study, internal consistency was good in the final sample for personal burnout $(\alpha=0.91)$, work-related burnout $(\alpha=0.79)$ and client-related burnout $(\alpha=0.87)$. Burnout was assessed in Phases 2 and 3 only.

\subsubsection{Coping}

Coping was assessed by two scales, the Strategies for Coping with Work and Family Stressors Scale [44] and the Brief COPE scale [45]. Only 20 items from the Brief COPE scale [45] were used to assess ten different coping strategies (active coping, planning, acceptance, positive reframing, use of emotional support, use of instrumental support, venting, substance use, behavioural disengagement, and self-blame). The scale assesses the frequency with which the respondent has been using the strategies described in the items using a four-point Likert scale ranging ( $1=$ 'I haven't been doing this at all' to $4=$ 'I've been doing this a lot'). The Cronbach's alpha for the 20-item scale was acceptable in this present study $(\alpha=0.82)$.

The 15 items from Clark et al.'s [44] scale assessed five different coping strategies (familywork segmentation, work-family segmentation, working to improve skills/efficiency, recreation and relaxation and exercise). Respondents indicated how often they had been doing what was derived by the statements on the six-point Likert scale $(1=$ 'Never have done this' to $6=$ 'Almost always do this') with a mean score for each domain computed. The Cronbach's alphas for the scale were acceptable in all phases in this present $(\alpha=0.83)$.

\subsection{Data Analysis}

All three datasets from the respective phases were recoded and merged into SPSS. Data analyses were conducted using SPSS 26 and any missing data were addressed prior to beginning the analysis. Respondents who did not complete all items on one or more of the scales (SWEMWBS, WRQoL, Brief COPE, and Clark's coping) were excluded from the merged dataset for all three phases $(n=2008)$. Those who indicated gender as neither or missing ( $n=26=0.3 \%$ ) were excluded as the subgroup sample was so low. The remaining missing data on the variables relevant to the analyses were minimal $(0.22 \%)$. The SWEMWBS, WRQoL, Burnout and the coping items were treated as continuous variables and missing data on these items were estimated using the EM algorithm for single imputa- 
tion in SPSS. Missing values on the demographic and work-related variables were minimal $(0.04 \%)$ and they were not estimated. Instead, listwise deletion was used in the analyses.

Preliminary analyses using descriptive statistics were conducted to provide basic information regarding the variables included in the study. Multivariate statistics using Mann-Whitney U and Kruskal-Wallis tests were used to examine the difference in the outcome variables, across the various scales for burnout, wellbeing, WRQoL and coping strategies; across the three study phases. To account for the different distribution of occupational groups and countries across the three study phases, descriptive statistics for the outcome variables (wellbeing, quality of working life, burnout, and coping strategies) were weighted by occupation and country.

\section{Results}

\subsection{Sample Characteristics}

The final sample across all three phases consisted of 7476 HSC respondents (Phase 1: $n=2546$; Phase 2: $n=2718$; Phase 3: $n=2212)$. Respondents were mainly white $(95.5 \%)$, predominately female (87.9\%), just under half had between 11 and 30 years' experience $(49.7 \%)$, one-third were in the $50-59$ age category $(31.4 \%)$, and nearly half of the respondents were from Northern Ireland (42.5\%). Over two-thirds of the sample were working in Social Care and Social Work (68.9\%). Just under half of the respondents worked in the community $(49.8 \%)$, with main areas of practice being with older people and other adults (43.3\%). Over half of the respondents were married (52.9\%), reported no disability $(87.2 \%)$ and had not been redeployed during the COVID-19 pandemic (86.9\%). A full breakdown of the demographics is reported in Table 1.

\subsection{Descriptive Statistics}

Descriptive statistics of the outcome variables for each phase are shown in Tables 2 and 3. The results showed that respondents' wellbeing and work-related quality of life decreased across each phase. Respondents appeared to be using several positive coping strategies less frequently (active coping, positive reframing, acceptance, use of emotional support and use of instrumental support, work-family segmentation, working to improve skills/efficiency, recreation and relaxation and exercise). However, many of the negative coping strategies were more frequently used as the phases of the study progressed (substance use, behavioural disengagement, and self-blame). All domains of burnout showed increased personal, workrelated, and client-related burnout between Phases 2 and 3 .

Table 2. Means and standard deviations (in brackets) for the wellbeing, work-related quality of life (WRQoL) and Burnout by occupation and across phases.

\begin{tabular}{lccccc}
\hline \multirow{2}{*}{ Variables } & \multicolumn{5}{c}{ Occupation } \\
\cline { 2 - 6 } & Social Work & Social Care & AHP & Midwifery & Nursing \\
\hline Wellbeing & & & & \\
Phase 1 & $21.32(3.34)$ & $20.90(3.92)$ & $21.32(3.32)$ & $20.87(3.24)$ & $21.15(3.68)$ \\
Phase 2 & $20.11(3.20)$ & $20.05(3.59)$ & $20.60(3.36)$ & $19.81(2.37)$ & $20.43(3.16)$ \\
Phase 3 & $19.83(3.25)$ & $19.82(3.89)$ & $20.72(3.87)$ & $19.28(3.08)$ & $20.59(3.47)$ \\
\hline WRQoL & & & & \\
Phase 1 & $80.67(13.58)$ & $79.16(15.62)$ & $82.06(12.42)$ & $77.43(15.28)$ & $75.11(18.64)$ \\
Phase 2 & $74.06(15.17)$ & $73.38(16.35)$ & $74.10(16.11)$ & $66.53(15.95)$ & $71.19(14.43)$ \\
Phase 3 & $69.78(15.97)$ & $70.69(15.73)$ & $75.16(18.34)$ & $64.80(12.83)$ & $74.57(15.30)$ \\
\hline Personal Burnout & & & & \\
Phase 2 & $62.86(19.81)$ & $54.17(22.84)$ & $57.00(17.96)$ & $66.76(13.59)$ & $62.74(18.39)$ \\
Phase 3 & $62.86(19.81)$ & $59.65(22.76)$ & $62.01(21.93)$ & $72.13(16.95)$ & $61.42(22.14)$ \\
\hline Work-related Burnout & & & & \\
Phase 2 & $60.45(19.91)$ & $59.74(20.76)$ & $54.77(20.55)$ & $66.21(18.98)$ & $57.55(18.94)$ \\
$\quad$ Phase 3 & $64.36(19.67)$ & $63.67(20.54)$ & $55.22(24.17)$ & $70.55(17.63)$ & $57.42(22.04)$ \\
\hline Client-related Burnout $)$ & & & & \\
$\quad$ Phase 2 & $30.63(20.53)$ & $25.49(20.30)$ & $28.17(19.44)$ & $31.02(22.67)$ & $28.21(20.49)$ \\
Phase 3 & $32.71(22.97)$ & $27.48(20.23)$ & $30.34(23.57)$ & $34.27(20.94)$ & $27.77(22.87)$ \\
\hline
\end{tabular}


Table 3. Means and standard deviations (in brackets) for wellbeing, work-related quality of life (WRQoL), coping strategies and burnout across study phases.

\begin{tabular}{|c|c|c|c|c|}
\hline \multirow{2}{*}{ Variable } & Phase $1(n=2546)$ & Phase $2(n=2718)$ & Phase $3(n=2212)$ & Phase Comparison \\
\hline & \multicolumn{3}{|c|}{ M (SD) } & $p$-Value \\
\hline Wellbeing & $20.96(3.78)$ & $20.21(3.36)$ & $20.18(3.81)$ & $<0.001$ \\
\hline Quality of working life & $78.09(17.50)$ & $72.53(15.92)$ & $71.98(15.88)$ & $<0.001$ \\
\hline \multicolumn{5}{|l|}{ Coping strategies } \\
\hline Active coping & $6.00(1.64)$ & $5.47(1.70)$ & $5.32(1.87)$ & $<0.001$ \\
\hline Planning & $5.81(1.81)$ & $5.52(1.86)$ & $5.57(1.74)$ & $<0.001$ \\
\hline Positive reframing & $5.85(1.65)$ & $5.57(1.70)$ & $5.37(1.69)$ & $<0.001$ \\
\hline Acceptance & $6.39(1.53)$ & $6.18(1.51)$ & $5.97(1.47)$ & $<0.001$ \\
\hline Use of emotional support & $4.93(1.77)$ & $4.74(1.83)$ & $4.69(1.76)$ & $<0.001$ \\
\hline Use of instrumental support & $4.34(1.83)$ & $4.30(1.79)$ & $4.11(1.74)$ & $<0.001$ \\
\hline Venting & $3.51(1.43)$ & $4.15(1.64)$ & $4.07(1.61)$ & $<0.001$ \\
\hline Substance use & $2.75(1.41)$ & $2.81(1.44)$ & $2.98(1.56)$ & $<0.001$ \\
\hline Behavioural disengagement & $2.73(1.25)$ & $3.00(1.37)$ & $3.22(1.53)$ & $<0.001$ \\
\hline Self-blame & $3.42(1.81)$ & $4.01(1.88)$ & $4.24(1.87)$ & $<0.001$ \\
\hline Family-work segmentation & $5.13(0.84)$ & $5.12(0.84)$ & $5.13(0.86)$ & 0.673 \\
\hline Work-family segmentation & $4.66(1.05)$ & $4.59(1.07)$ & $4.44(1.25)$ & $<0.001$ \\
\hline Working to improve skills/efficiency & $4.49(1.09)$ & $4.18(1.15)$ & $4.23(1.12)$ & $<0.001$ \\
\hline Recreation and relaxation & $3.75(1.23)$ & $3.55(1.31)$ & $3.46(1.22)$ & $<0.001$ \\
\hline Exercise & $3.97(1.41)$ & $3.65(1.38)$ & $3.34(1.41)$ & $<0.001$ \\
\hline \multicolumn{5}{|l|}{ Burnout } \\
\hline Personal & Not measured & $61.21(19.77)$ & $63.60(21.17)$ & $<0.001$ \\
\hline Work-related & Not measured & $56.33(21.10)$ & $60.32(21.72)$ & $<0.001$ \\
\hline Client-related & Not measured & $27.95(20.35)$ & $29.74(21.76)$ & $<0.001$ \\
\hline
\end{tabular}

\subsection{Mulitvariate Analysis}

Data were not normally distributed and therefore Kruskal-Wallis $\mathrm{H}$ tests were used to compare the scores on wellbeing, work-related quality of life, and the domains of coping. As burnout was only measured in Phases 2 and 3, Mann-Whitney U tests were performed for each domain. The results showed that wellbeing and overall WRQoL significantly differed across the occupation groups in Phases 1,2 and $3(p<0.05)$. The results showed that wellbeing $(\mathrm{H}(2)=112.45, p<0.001)$ significantly declined across the Phases. Phase 1 respondents reported the highest wellbeing (20.96), compared to Phase 2 (20.21) and Phase 3 (20.18). Dunn's pairwise comparison (adjusted using Bonferroni correction) revealed a significant difference between wellbeing in Phase 1 and $3(p<0.001)$ while no significant difference between Phases 2 and 3 ( $p=0.099$ ) was found. Overall WRQoL (H (2) $=305.52$, $p<0.001$ ) significantly decreased across the three phases, with a mean rank wellbeing score of 78.09 for Phase 1, 72.53 for Phase 2 and 71.98 for Phase 3. Dunn's pairwise comparison revealed a significant difference in overall WRQoL between Phases 1 and $3(p<0.001)$ with no significant difference between Phases 2 and $3(p=0.355)$.

Active coping $(\mathrm{H}(2)=255.71, p<0.001)$, positive reframing $(\mathrm{H}(2)=125.1, p<0.001)$, acceptance $(\mathrm{H}(2)=140.72, p<0.001)$, use of emotional support, $(\mathrm{H}(2)=30.64, p<0.001)$, use of instrumental support $(\mathrm{H}(2)=23.73, p<0.001)$, work-family segmentation $(\mathrm{H}(2)=50.03$, $p<0.001)$, working to improve skills/efficiency $(\mathrm{H}(2)=139.37, p<0.001)$, recreation and relaxation $(\mathrm{H}(2)=82.89, p<0.001)$, exercise $(\mathrm{H}(2)=317.67, p<0.001)$ and venting $(\mathrm{H}(2)=281.17, p<0.001)$ all significantly decreased across the phases. Planning $(\mathrm{H}(2)=49.38, p<0.001)$, Self-blame $(\mathrm{H}(2)=353.94, p<0.001)$, Substance use $(\mathrm{H}(2)=40.04$, $p<0.001)$ and behavioural disengagement $(\mathrm{H}(2)=201.61, p<0.001)$ were coping strategies which all significantly increased across the phases. Family-work segmentation was the only coping strategy to exhibit no significant difference across the phases $(\mathrm{H}(2)=0.673$, $p=0.793)$.

Mann-Whitney $U$ tests showed that personal burnout $(U=2947950.5, p<0.001$, $\mathrm{r}=0.08)$, work-related burnout $(\mathrm{U}=3095879.5, p<0.001, \mathrm{r}=0.13)$, and client-related burnout $(\mathrm{U}=2794055.5, p=0.02, \mathrm{r}=0.04)$, were all significantly higher in Phase 3 compared to Phase 2. Personal burnout significantly increased between Phase 2 and 3 for 
AHPs $U=73636.5, p<0.01)$, social care workers $(\mathrm{U}=59361, p<0.001)$ and social workers $(\mathrm{U}=670174.5, p<0.001)$. Work-related burnout significantly increased between Phase 2 and 3 for social care workers $(U=61551, p<0.001)$ and social workers $(U=659191.5$, $p<0.001)$. For client-related burnout only social care workers had a significantly higher score between the Phases 2 and $3(U=609925.500, p<0.05)$. Overall midwives had the lowest wellbeing and WRQoL scores but also exhibited the highest levels of personal, workrelated and client burnout. For the overall sample, there was an increase in high-severe personal burnout from $27.6 \%$ in Phase 2, to 36.5\% in Phase 3; high-severe work-related burnout increased from $20.8 \%$ to $26 \%$, while high-severe client-related burnout increased from $2.0 \%$ to $3.2 \%$, respectively.

\section{Discussion}

\subsection{Main Messages in Comparison with the Literature}

The aim of the present paper is to compare cross-sectional data collected from nurses, midwives, AHPs, social care workers and social workers in the UK at three different time points (Phase 1: May-July 2020; Phase 2: Nov 2020-Jan 2021; Phase 3: May-July 2021) during the COVID-19 pandemic. The results showed that, at all time points, average mental wellbeing scores in this study are nearly three points lower than previously reported, as the population Norm has been reported as a mean score of $23.6[37,46]$. These findings are also lower than previous UK findings pre-pandemic in which a mean score of 25.2 (3.1) was recorded in community nurses [47]. While similarities during the pandemic have been reported by Sumner \& Kinsella [48] amongst UK and Ireland HSC respondents who recorded a mean SWEWBS score of 22.7 (4.91); Smith et al. [49] reported a mean SWEWBS score of 20.8 (5.1) in UK based respondents. A study by Dawson and GoliganiMoghaddam [50] also found a mean SWEWBS score of 20.21 (3.97) across the general UK population, suggesting that both HSC workers and the general public have been severely affected in terms of their wellbeing due to the ongoing pandemic. This suggests that the pandemic may potentially influence the wellbeing of the HSC workforce due to the increased demands and changes within their personal life due to COVID-19-related problems and stressors.

In this current analysis, WRQoL scores decreased from a mean score of 78.09 (17.50) in Phase 1 to 71.98 (15.88) in Phase 3. With these phases conducted a year apart, these results indicate a significant decrease in WRQoL scores. Social Workers, Social Care workers and midwives continued to show a decline in WRQoL scores over Phases 1, 2 and 3; this could be a result of the change to their working conditions, with many of these respondents experiencing restrictions to their jobs or having to work from home. The findings from Phase 1 are comparable to the mean normative score of $3.44(78.09 / 23=3.40)$ derived from the UK NHS workforce study [51]; however, as the pandemic continued, results in Phase $2(72.53 / 23=3.15)$ and Phase $3(71.98 / 23=3.13)$ were considerably lower. Moreover, the findings of this study also coincide with average quality of working life reported by Easton et al. [51]. Mendes and Pereira [52] reported a value of 3.40 in the general Portuguese working population, suggesting that healthcare workers may have lower WRQoL. Pre-pandemic, within the AHPs, one study reported WRQoL scores of 82.92 (14.17) for occupational therapists in Iran [53] while another study of Vietnam's healthcare professionals reported higher scores of 95.52 and 92.10 during the pandemic [54], suggesting that these professionals had higher WRQoL than UK-based respondents. However, during the pandemic, lower scores have been reported amongst nurses in hospitals in Iran [55,56], suggesting that country of work and different working practices could influence total WRQoL.

Burnout (measured in Phases 2 and 3 only) was found to significantly increase during the pandemic for the respondents surveyed. Work-related burnout was much higher in this study (Phase 2-56.33 and Phase 3-60.32) than reported among NHS staff in the UK earlier in the pandemic, with Gemine et al. [57] stating work-related burnout to be 45.7 (15.7), suggesting that redeployment and changing advice and conditions may result in increased burnout; a similar rationale may be attributed to this study. Additionally, the 
findings in this present study are higher than previous findings from healthcare workers in India [58] in which personal burnout was reported as 49.72 (18.68) and work-related burnout as 39.39 (20.43). A study of healthcare workers in Portugal measured burnout as low or high; high personal burnout was reported at $52.5 \%$, high work-related burnout $53.1 \%$ and $35.4 \%$ had high client-related burnout [59]. In comparison with this present study (with moderate-severe categories combined for comparison), HSC workers in the UK experienced higher levels of high personal (74.2\%) and work-related burnout (66.0\%) but lower client-related burnout (20.1\%).

As the pandemic continued, our results indicate that more negative avoidant coping strategies (substance use, behavioural disengagement and self-blame) were being adopted by the HSC workforce and less use of more positive approach type strategies (active coping, positive reframing, acceptance, use of emotional support, use of instrumental support). Similarities in the mean scores over the three phases can be found with a longitudinal study in Belgium by Van Steenkiste et al. [60], with the suggestion that avoidance strategies worsen from the first time point as the pandemic continued, though these authors reported no significant difference in coping over time in Belgian healthcare workers, whereas this current study found a significant difference. A study by Cansiz et al. [61] examined coping among Turkish healthcare professionals reporting that frontline workers used more acceptance and active coping strategies than non-frontline workers during the pandemic. In comparison with this present study, Cansiz et al. [61] reported higher use of negative strategies, such as self-blame, substance use, emotional support and behavioural disengagement, but also higher use of planning and emotional support strategies. Studies from Canestrari et al. [62] in Italy and Vera-Monge et al. [63] in Spain reported lower scores for the usage of positive approach strategies and negative avoidant strategies, while a study involving Greek healthcare professionals reported higher scores for the usage of positive approach strategies and lower usage of avoidant strategies than this present study [64].

Engaging in the negative, more avoidant coping strategies was also found in our earlier study phases [32-34] and within the literature, with the usage of these strategies being found to have a negative relationship and impact on mental wellbeing and resulting in increased burnout within the HSC workforce [50,60,62,63,65-67]. Amongst respondents in Phase 3 of this present study there was widespread recognition that pandemic-related work responsibilities had affected respondents' quality of home life, with working from home not enabling a break from work for many of this workforce and it was noted that an emphasis should be placed on re/creating a more healthy work-life balance [68]. Overall, evidence suggests that the use of positive coping strategies are essential in reducing stressors, improving wellbeing and work-related quality of life which can then reduce burnout [64,69-71].

\subsection{Limitations and Strengths}

This study has several limitations. While this study highlights any statistically significant associations between the examined outcomes, the study design for each phase of the research was cross-sectional, thus only providing a snapshot of the outcomes at that specific point of time. In cross-sectional studies it is impossible to infer causality which limits evaluation of associations between outcomes [72,73]. However, a benefit of repeated cross-sectional studies is that they can provide information over time to inform public health planning and policies, which is important in the sustainability of the HSC workforce. Additionally, a strength of this study is the time periods in which the data were collected as this represents different levels of pressures for the workforce during the pandemic. The survey is self-report therefore may be subject to recall bias or social desirability bias [74,75], although the surveys were anonymous. Another limitation is that a majority of respondents were from the social care and social work sectors (68.9\%) and therefore not representative of the whole health and social care sector. This may have been the result of other workforce surveys in the healthcare sector/NHS which were directed at nurses, midwives and AHPs. As noted previously, data were weighted to account for the different distribution of occupational groups and countries across the three study phases, 
which diminishes the effects of inherent biases of the survey, addresses sampling and none response bias, while allowing for a more accurate representation of the population under examination $[76,77]$.

Data were collected online using a convenience sampling method through extensive sharing of a survey link through social media platforms. While this was an efficient, simple and pragmatic way to safely gather data from a large sample during the COVID-19 pandemic, it may increase the risk of selection bias in that the sample may be over-representative either of workers with sufficient time to complete a survey, or those concerned about the wellbeing of themselves and colleagues and therefore more motivated to register their views $[74,78,79]$. This therefore can result in a lack of clear generalisability within the results and increased risk of bias [80]. Additionally, recruiting a sample which ethnically resembles the workforce has proven a challenge and most of respondents within this study identify as white ethnicity (95.5\%), which may be a result of the convenience sampling technique utilised. We did not assess any previous co-morbidities among respondents and the presence of these co-morbidities might have influenced how mental-wellbeing, work-related quality of life and coping were reported.

\subsection{Implications}

As the HSC sector begins to rebuild pre-pandemic services, several elements must be addressed to prevent further burden on this already stretched workforce. Protecting and managing the mental wellbeing and quality of working life of those working in HSC is necessary for long-term sustainability of the workforce and the services they provide. Managing fresh challenges, preparing for possible future epidemic/pandemics and providing ongoing support are crucial. There is still some uncertainty for the future deployment of this workforce therefore new or updated supports and policies need to be reviewed and implemented. It is important to manage coping strategies as there was significant decline in the number of positive strategies used from May 2020 to July 2021. Based on our good-practice recommendations [68] which emerged from the data, sustained support needs to occur across three system levels (individual, organisational and policy).

The pandemic has further highlighted problems within the HSC system and, as job demands increase and will continue to do so in the aftermath of COVID-19, communication will be important for employers to maintain and develop. Signposting staff to services for mental health and wellbeing will be important, while highlighting that staff are valued is essential for cohesion and job satisfaction. Furthermore, evidence also suggests that support may help mitigate some of the negative impacts of COVID-19 on HSC staff, particularly continued support from leaders and supervisors while being provided relevant and honest information about COVID-19 to respond to changing conditions of work $[81,82]$. The unprecedented pressure on HSC has shone a light on the persistent under-resourcing of staff and infrastructure. Therefore, concerted efforts are required to make work attractive and welcoming. Another implication of these findings is that wellbeing and work-related quality of life may improve with more flexibility in employment, through regular breaks and possible options to work from home. Flexibility in the workplace has been acknowledged as reducing the stressors around work-life balance which may in the long-term significantly improve mental health and quality of life as it can increase resilience [83-85].

\section{Conclusions}

In summary, our findings support other research which highlights that the COVID-19 pandemic has been overwhelming for the much of the HSC sector. While most of the HSC workforce has been resilient throughout this crisis, continuing changes to home-work life, job responsibilities and increased work-related pressures worsened by the COVID-19 pandemic could have a lasting impact on wellbeing, coping, burnout and work-related quality of life. With few studies assessing these outcomes across the HSC workforce, it is important for research to examine the long-term impact of the pandemic on the frontline of care and to compare each outcome across the different occupations 


\begin{abstract}
Author Contributions: Conceptualisation, P.M. and P.G.; formal analysis, R.D.N.; funding acquisition, P.M. and P.G.; investigation, P.M. and P.G.; methodology, P.M. and P.G.; project administration, P.M.; supervision, P.G.; writing—original draft, R.D.N.; writing—review and editing, R.D.N., P.G., J.M. (John Mallett), H.S., P.N., J.M. (Jill Manthorpe), J.M. (John Moriarty), J.R., D.C., S.M. and P.M. All authors have read and agreed to the published version of the manuscript.
\end{abstract}

Funding: This study is funded by HSC R\&D Division of the Public Health Agency, Northern Ireland (COVID Rapid Response Funding Scheme COM/5603/20), seed funding from the Northern Ireland Social Care Council (NISCC) and the Southern Health and Social Care Trust, with support from England's National Institute for Health Research (NIHR) Policy Research Unit in Health and Social Care Workforce at King's College London (grant number NIHR PR-PRU-1217-21002).

Institutional Review Board Statement: This study was conducted according to the guidelines of the Declaration of Helsinki and approved by Filter Ethics Committee in the School of Nursing at Ulster University (Ref No: 2020/5/3.1, 23 April 2020 Ulster University; Ulster University IRAS Ref No: 20/0073).

Informed Consent Statement: Informed consent was obtained from all subjects involved in this study.

Data Availability Statement: The data presented in this study are available on request from the corresponding author. The data are not publicly available due to ethical restrictions.

Acknowledgments: The authors thank all respondents, the Northern Ireland Social Care Council (NISCC), and the Southern Health and Social Care Trust in Northern Ireland for seed funding for the survey. Moreover, thanks to Community Care $\bigodot$, Northern Ireland Practice and Education Council for Nursing and Midwifery, Royal College of Nursing, Royal College of Midwifery, Royal College of Occupational Therapists, British Dietetic Association, College of Podiatry, and the NISCC for advertising and promoting the study.

Conflicts of Interest: The authors declare no conflict of interest. The funders had no role in the design of the study; in the collection, analyses, or interpretation of data; in the writing of the manuscript, or in the decision to publish the results. The views expressed are those of the authors and not necessarily those of the funders, or the NIHR or Department of Health and Social Care.

\title{
References
}

1. World Health Organization. Rolling Updates on Coronavirus (COVID-19). 2022. Available online: https://www.who.int/ emergencies/diseases/novel-coronavirus-2019/events-as-they-happen (accessed on 10 November 2021).

2. Keshky, E.; El Sayed, M.; Basyouni, S.S.; Al Sabban, A.M. Getting through covid-19: The pandemic's impact on the psychology of sustainability, quality of life, and the global economy-A systematic review. Front. Psychol. 2020, 11, 3188. [CrossRef] [PubMed]

3. Mofijur, M.; Fattah, I.M.R.; Alam, M.A.; Islam, A.; Ong, H.C.; Rahman, S.M.A.; Najafi, G.; Ahmed, S.F.; Uddin, M.A.; Mahlia, T.M.I. Impact of COVID-19 on the social, economic, environmental and energy domains: Lessons learnt from a global pandemic. Sustain. Prod. Consum. 2021, 26, 343-359. [CrossRef] [PubMed]

4. Bashir, M.F.; Benjiang, M.A.; Shahzad, L. A brief review of socio-economic and environmental impact of Covid-19. Air Qual. Atmos. Health 2020, 13, 1403-1409. [CrossRef] [PubMed]

5. World Health Organisation. WHO Coronavirus (COVID-19) Dashboard. 2022. Available online: https://covid19.who.int/table (accessed on 4 January 2022).

6. World Health Organization. Getting Your Workplace Ready for COVID-19. 2020. Available online: https://www.who.int/docs/ default-source/coronaviruse/getting-workplace-ready-for-covid-19.pdf (accessed on 10 November 2021).

7. World Health Organization. Handwashing an Effective Tool to Prevent COVID-19, Other Diseases 2020. Available online: https:/ / www.who.int/southeastasia/news/detail/15-10-2020-handwashing-an-effective-tool-to-prevent-covid-19-otherdiseases\#: \{\}:text=To\%20stop\%20the\%20spread\%20of,handling\%20animals\%20or\%20animal\%20waste (accessed on 10 November 2021).

8. Goniewicz, K.; Khorram-Manesh, A. Maintaining Social Distancing during the COVID-19 Outbreak. Soc. Sci. 2021, 10, 14. [CrossRef]

9. Chiu, N.C.; Chi, H.; Tai, Y.L.; Peng, C.C.; Tseng, C.Y.; Chen, C.C.; Tan, B.F.; Lin, C.Y. Impact of wearing masks, hand hygiene, and social distancing on influenza, enterovirus, and all-cause pneumonia during the coronavirus pandemic: Retrospective national epidemiological surveillance study. J. Med. Internet Res. 2020, 22, e21257. [CrossRef] [PubMed]

10. Barrett, C.; Cheung, K.L. Knowledge, socio-cognitive perceptions and the practice of hand hygiene and social distancing during the COVID-19 pandemic: A cross-sectional study of UK university students. BMC Public Health 2021, 21, 426. [CrossRef]

11. King's Fund. Overview of the Health and Social Care Workforce. 2021. Available online: https://www.kingsfund.org.uk/ projects/time-think-differently/trends-workforce-overview (accessed on 10 November 2021). 
12. Warner, M.; Zaranko, B. Pressures on the NHS. 2021. Available online: https:/ /ifs.org.uk/uploads/6-Pressures-on-the-NHS-.pdf (accessed on 10 November 2021).

13. Charlesworth, A.; Johnson, P.; Firth, Z.; Gershlick, B.; Watt, T.; Kelly, E.; Lee, T.; Stoye, G.; Zaranko, B. Securing the Future: Funding Health and Social Care to the 2030s; The Institute for Fiscal Studies: London, UK, 2018; Available online: https:/ /ifs.org.uk/ uploads/R143.pdf (accessed on 10 November 2021).

14. NHS Providers. Steeling Ourselves for Winter 2018/19. 2019. Available online: https://nhsproviders.org/steeling-ourselves-forwinter-201819 (accessed on 10 November 2021).

15. Authority of the House of Lords. The Long-Term Sustainability of the NHS and Adult Social Care; Authority of the House of Lords: London, UK, 2017.

16. Brophy, J.T.; Keith, M.M.; Hurley, M.; McArthur, J.E. Sacrificed: Ontario healthcare workers in the time of COVID-19. New Solut. J. Environ. Occup. Health Policy 2021, 30, 267-281. [CrossRef]

17. House of Commons. Workforce Burnout and Resilience in the NHS and Social Care. 2021. Available online: https://committees parliament.uk/publications/6158/documents/68766/default/ (accessed on 10 November 2021).

18. De Kock, J.H.; Latham, H.A.; Leslie, S.J.; Grindle, M.; Munoz, S.A.; Ellis, L.; Polson, R.; O’Malley, C.M. A rapid review of the impact of COVID-19 on the mental health of healthcare workers: Implications for supporting psychological well-being. BMC Public Health 2021, 21, 104. [CrossRef]

19. Charles, A.; Ewbank, L. The Road to Renewal: Five Priorities for Health and Care. 2021. Available online: https://www. kingsfund.org.uk/publications/covid-19-road-renewal-health-and-care (accessed on 10 November 2021).

20. OECD. Enhancing Public Trust in COVID-19 Vaccination: The Role of Governments. 2021. Available online: https://www.oecd org/coronavirus / policy-responses / enhancing-public-trust-in-covid-19-vaccination-the-role-of-governments-eae0ec5a/ (accessed on 10 November 2021).

21. Martinelli, L.; Kopilaš, V.; Vidmar, M.; Heavin, C.; Machado, H.; Todorović, Z.; Buzas, N.; Pot, M.; Prainsack, B.; Gajović, S. Face masks during the COVID-19 pandemic: A simple protection tool with many meanings. Front. Public Health 2020, 8, 606635. [CrossRef]

22. Van Bavel, J.J.; Baicker, K.; Boggio, P.S.; Capraro, V.; Cichocka, A.; Cikara, M.; Crockett, M.J.; Crum, A.J.; Douglas, K.M.; Druckman, J.N.; et al. Using social and behavioural science to support COVID-19 pandemic response. Nat. Hum. Behav. 2020, 4, 460-471. [CrossRef]

23. Cotel, A.; Golu, F.; Pantea Stoian, A.; Dimitriu, M.; Socea, B.; Cirstoveanu, C.; Davitoiu, A.M.; Jacota Alexe, F.; Oprea, B. Predictors of burnout in healthcare workers during the COVID-19 pandemic. Healthcare 2021, 9, 304. [CrossRef]

24. Cabarkapa, S.; Nadjidai, S.E.; Murgier, J.; Ng, C.H. The psychological impact of COVID-19 and other viral epidemics on frontline healthcare workers and ways to address it: A rapid systematic review. Brain Behav. Immun. Health 2020, 17, 100144. [CrossRef] [PubMed]

25. Naldi, A.; Vallelonga, F.; Di Liberto, A.; Cavallo, R.; Agnesone, M.; Gonella, M.; Sauta, M.D.; Lochner, P.; Tondo, G.; Bragazzi, N.L.; et al. COVID-19 pandemic-related anxiety, distress and burnout: Prevalence and associated factors in healthcare workers of North-West Italy. BJPsych Open 2021, 7, e27. [CrossRef]

26. Billings, J.; Abou Seif, N.; Hegarty, S.; Ondruskova, T.; Soulios, E.; Bloomfield, M.; Greene, T. What support do frontline workers want? A qualitative study of health and social care workers' experiences and views of psychosocial support during the COVID-19 pandemic. PLoS ONE 2021, 16, e0256454. [CrossRef]

27. World Health Organization. Strengthening the Health System Response to COVID-19. 2020. Available online: https://apps.who int/iris/handle/10665/332559 (accessed on 10 November 2021).

28. Apaydin, E.A.; Rose, D.E.; Yano, E.M.; Shekelle, P.G.; McGowan, M.G.; Antonini, T.L.; Valdez, C.A.; Peacock, M.; Probst, L.; Stockdale, S.E. Burnout Among Primary Care Healthcare Workers During the COVID-19 Pandemic. J. Occup. Environ. Med. 2021, 63, 642. [CrossRef]

29. Chor, W.P.; Ng, W.M.; Cheng, L.; Situ, W.; Chong, J.W.; Ng, L.Y.; Mok, P.L.; Yau, Y.W.; Lin, Z. Burnout amongst emergency healthcare workers during the COVID-19 pandemic: A multi-center study. Am. J. Emerg. Med. 2021, 46, 700. [CrossRef]

30. Harrikari, T.; Romakkaniemi, M.; Tiitinen, L.; Ovaskainen, S. Pandemic and Social Work: Exploring Finnish Social Workers' Experiences through a SWOT Analysis. Br. J. Soc. Work 2021, 29, bcab052. [CrossRef]

31. Barello, S.; Palamenghi, L.; Graffigna, G. Burnout and somatic symptoms among frontline healthcare professionals at the peak of the Italian COVID-19 pandemic. Psychiatry Res. 2020, 290, 113129. [CrossRef] [PubMed]

32. McFadden, P.; Ross, J.; Moriarty, J.; Mallett, J.; Schroder, H.; Ravalier, J.; Manthorpe, J.; Currie, D.; Harron, J.; Gillen, P. The role of coping in the wellbeing and work-related quality of life of UK health and social care workers during COVID-19. Int. J. Environ. Res. Public Health 2021, 18, 815. [CrossRef] [PubMed]

33. McFadden, P.; Neill, R.D.; Moriarty, J.; Gillen, P.; Mallett, J.; Manthorpe, J.; Currie, D.; Schroder, H.; Ravalier, J.; Nicholl, P.; et al. A cross-sectional examination of the mental wellbeing, coping and quality of working life in health and social care workers in the UK at two time points of the COVID-19 pandemic. Epidemiologia 2021, 2, 227-242. [CrossRef]

34. McFadden, P.; Neill, R.D.; Mallett, J.; Manthorpe, J.; Gillen, P.; Moriarty, J.; Currie, D.; Schroder, H.; Ravalier, J.; Nicholl, P.; et al Mental well-being and quality of working life in UK social workers before and during the COVID-19 pandemic: A propensity score matching study. Br. J. Soc. Work 2021. [CrossRef] 
35. Manthorpe, J.; Iliffe, S.; Gillen, P.; Moriarty, J.; Mallett, J.; Schroder, H.; Currie, D.; Ravalier, J.; McFadden, P. Clapping for carers in the Covid-19 crisis: Carers' reflections in a UK survey. Health Soc. Care Community 2021. [CrossRef] [PubMed]

36. Stewart-Brown, S.; Tennant, A.; Tennant, R.; Platt, S.; Parkinson, J.; Weich, S. Internal construct validity of theWarwick-Edinburgh Mental Well-being Scale (WEMWBS): A Rasch analysis using data from the Scottish Health Education Population Survey. Health Qual. Life Outcomes 2009, 7, 15. [CrossRef]

37. Fat, L.N.; Scholes, S.; Boniface, S.; Mindell, J.; Stewart-Brown, S. Evaluating and establishing national norms for mental wellbeing using the short Warwick-Edinburgh Mental Well-being Scale (SWEMWBS): Findings from the Health Survey for England. Qual. Life Res. 2017, 26, 1129-1144. [CrossRef] [PubMed]

38. Koushede, V.; Lasgaard, M.; Hinrichsen, C.; Meilstrup, C.; Nielsen, L.; Rayce, S.B.; Torres-Sahli, M.; Gudrun Gudmundsdottir, D.; Stewart-Brown, S.; Santini, Z.I. Measuring mental well-being in Denmark: Validation of the original and short version of the Warwick-Edinburgh mental well-being scale (WEMWBS and SWEMWBS) and cross-cultural comparison across four European settings. Psychiatry Res. 2019, 271, 502-509. [CrossRef] [PubMed]

39. Van Laar, D.; Edwards, J.A.; Easton, S. The Work-Related Quality of Life scale for healthcare workers. J. Adv. Nurs. 2007, 60, 325-333. [CrossRef] [PubMed]

40. Lebni, J.Y.; Toghroli, R.; Abbas, J.; Kianipour, N.; NeJhaddadgar, N.; Salahshoor, M.R.; Chaboksavar, F.; Moradi, F.; Ziapour, A Nurses' work-related quality of life and its influencing demographic factors at a public hospital in western Iran: A Cross-Sectional Study. Int. Q. Community Health Educ. 2020, 42, 37-45. [CrossRef] [PubMed]

41. Kristensen, T.S.; Borritz, M.; Villadsen, E.; Christensen, K.B. The Copenhagen Burnout Inventory: A new tool for the assessment of burnout. Work Stress 2005, 19, 192-207. [CrossRef]

42. Creedy, D.K.; Sidebotham, M.; Gamble, J.; Pallant, J.; Fenwick, J. Prevalence of burnout, depression, anxiety and stress in Australian midwives: A cross-sectional survey. BMC Pregnancy Childbirth 2017, 17, 13. [CrossRef]

43. Thrush, C.R.; Gathright, M.M.; Atkinson, T.; Messias, E.L.; Guise, J.B. Psychometric properties of the Copenhagen Burnout Inventory in an academic healthcare institution sample in the US. Eval. Health Prof. 2020, 44, 400-405. [CrossRef]

44. Clark, M.A.; Michel, J.S.; Early, R.J.; Baltes, B.B. Strategies for Coping with Work Stressors and Family Stressors: Scale Development and Validation. J. Bus. Psychol. 2014, 29, 617-638. [CrossRef]

45. Carver, C.S. You want to measure coping but your protocol's too long: Consider the brief cope. Int. J. Behav. Med. 1997, 4, 92-100. [CrossRef] [PubMed]

46. NHS. Health Survey for England. 2011. Available online: https://digital.nhs.uk/data-and-information/publications/statistical/ health-survey-forengland/health-survey-for-england-2011-health-social-care-and-lifestyles (accessed on 18 July 2021).

47. Durkin, M.; Beaumont, E.; Martin, C.J.; Carson, J. A pilot study exploring the relationship between self-compassion, selfjudgement, self-kindness, compassion, professional quality of life and wellbeing among UK community nurses. Nurse Educ. Today 2016, 46, 109-114. [CrossRef] [PubMed]

48. Sumner, R.C.; Kinsella, E.L. Grace under Pressure: Resilience, Burnout, and Wellbeing in Frontline Workers in the United Kingdom and Republic of Ireland during the SARS-CoV-2 Pandemic. Front. Psychol. 2021, 27, 3757. [CrossRef] [PubMed]

49. Smith, L.; Jacob, L.; Yakkundi, A.; McDermott, D.; Armstrong, N.C.; Barnett, Y.; López-Sánchez, G.F.; Martin, S.; Butler, L.; Tully, M.A. Correlates of symptoms of anxiety and depression and mental wellbeing associated with COVID-19: A cross-sectional study of UK-based respondents. Psychiatry Res. 2020, 291, 113138. [CrossRef]

50. Dawson, D.L.; Golijani-Moghaddam, N. COVID-19: Psychological flexibility, coping, mental health, and wellbeing in the UK during the pandemic. J. Contextual Behav. Sci. 2020, 17, 126-134. [CrossRef]

51. Easton, S.; Van Laar, D. User Manual for the Work-Related Quality of Life (WRQoL) Scale: A Measure of Quality of Working Life; University of Portsmouth: Portsmouth, UK, 2018.

52. Mendes, C.; Pereira, H. Assessing the impact of COVID-19 on work-related quality of life through the lens of sexual orientation. Behav. Sci. 2021, 11, 58. [CrossRef]

53. Rostami, H.R.; Akbarfahimi, M.; Ghaffari, A.; Kamali, M.; Rassafiani, M. Relationship between Work-Related Quality of Life and Job Satisfaction in Iranian Occupational Therapists. Occup. Ther. Int. 2021, 2021, 6692752. [CrossRef]

54. Vu, T.Q.; Nguyen, B.T.; Pham, V.N.; Nguyen, N.H.; Nguyen, T.T.; Vo, N.X.; Ngo, N.M.; Vo, T.Q. Quality of Work Life in Healthcare: A Comparison of Medical Representatives and Hospital Pharmacists. Hosp. Top. 2021, 99, 161-170. [CrossRef]

55. Khajehnasiri, F.; Foroushani, A.R.; Kashani, B.F.; Kassiri, N. Evaluation of the quality of working life and its effective factors in employed nurses of Tehran University of Medical Sciences Hospitals. J. Educ. Health Promot. 2021, 10, 112.

56. Farhadi, A.; Bagherzadeh, R.; Moradi, A.; Nemati, R.; Sadeghmoghadam, L. The relationship between professional self-concept and work-related quality of life of nurses working in the wards of patients with COVID-19. BMC Nurs. 2021, 20, 75. [CrossRef] [PubMed]

57. Gemine, R.; Davies, G.R.; Tarrant, S.; Davies, R.M.; James, M.; Lewis, K. Factors associated with work-related burnout in NHS staff during COVID-19: A cross-sectional mixed methods study. BMJ Open 2021, 11, e042591. [CrossRef] [PubMed]

58. Khasne, R.W.; Dhakulkar, B.S.; Mahajan, H.C.; Kulkarni, A.P. Burnout among healthcare workers during COVID-19 pandemic in India: Results of a questionnaire-based survey. Indian J. Crit. Care Med. 2020, 24, 664. [CrossRef] [PubMed]

59. Duarte, I.; Teixeira, A.; Castro, L.; Marina, S.; Ribeiro, C.; Jácome, C.; Martins, V.; Ribeiro-Vaz, I.; Pinheiro, H.C.; Silva, A.R.; et al. Burnout among Portuguese healthcare workers during the COVID-19 pandemic. BMC Public Health 2020, 20, 1885. [CrossRef] 
60. Van Steenkiste, E.; Schoofs, J.; Gilis, S.; Messiaen, P. Mental health impact of COVID-19 in frontline healthcare workers in a Belgian Tertiary care hospital: A prospective longitudinal study. Acta Clin. Belg. 2021, 7. [CrossRef]

61. Cansız, A.; Aydın, M.; Kandeğer, A.; Tan, Ö.; Kürşat Altınbaş, M.D. Evaluation of the Relationships between State-Trait Anxiety, Coping Strategies and Perceived Social Support among Frontline and Non-Frontline Health Workers during the COVID-19 Pandemic in Turkey. Isr. J. Psychiatry 2021, 58, 10-18.

62. Canestrari, C.; Bongelli, R.; Fermani, A.; Riccioni, I.; Bertolazzi, A.; Muzi, M.; Burro, R. Coronavirus disease stress among Italian healthcare workers: The role of coping humor. Front. Psychol. 2021, 11, 3962. [CrossRef]

63. Vera-Monge, V.A.; Alier, M.; Alarcon-Ruiz, C.A.; Artigas-Graells, N.; Perez-Franco, M.; Aupí-Escarrà, S.; Boix-Lago, A.; TorralbaCalero, M.; DuránNúñez, A.; Cañete-Abajo, N.; et al. Burnout Syndrome and Stress Coping in Healthcare Workers in COVID-19 Era. J. Psychiatry Psychiatr. Disord. 2021, 5, 140-152. [CrossRef]

64. Kalaitzaki, A.; Tamiolaki, A.; Tsouvelas, G. From secondary traumatic stress to vicarious posttraumatic growth amid COVID-19 lockdown in Greece: The role of health care workers' coping strategies. Psychol. Trauma Theory Res. Pract. Policy 2021. [CrossRef]

65. Singh, J.; Sood, M.; Chadda, R.K.; Singh, V.; Kattula, D. Mental health issues and coping among health care workers during COVID19 pandemic: Indian perspective. Asian J. Psychiatry 2021, 61, 102685. [CrossRef]

66. Peinado, M.; Anderson, K.N. Reducing social worker burnout during COVID-19. Int. Soc. Work. 2020, 63, 757-760. [CrossRef]

67. Franza, F.; Basta, R.; Pellegrino, F.; Solomita, B.; Fasano, V. The role of fatigue of compassion, burnout and hopelessness in healthcare: Experience in the time of COVID-19 outbreak. Psychiatr. Danub. 2020, 32 (Suppl. S1), 10-14. [PubMed]

68. McFadden, P.; Gillen, P.; Moriarty, J.; Mallett, J.; Schroder, H.; Ravalier, J.; Manthorpe, J.; Currie, D.; Nicholl, P.; Neill, R.D.; et al. COVID-19 Health and Social Care Workforce Study: Phase 3-May-July 2021; Ulster University: Coleraine, UK, 2021.

69. Usman, M.; Cheng, J.; Ghani, U.; Gul, H.; Shah, W.U. Social support and perceived uncertainties during COVID-19: Consequences for employees' wellbeing. Curr. Psychol. 2021. [CrossRef] [PubMed]

70. Velana, M.; Rinkenauer, G. Individual-Level Interventions for Decreasing Job-Related Stress and Enhancing Coping Strategies among Nurses: A Systematic Review. Front. Psychol. 2021, 12, 2970. [CrossRef]

71. Balasubramanian, A.; Paleri, V.; Bennett, R.; Paleri, V. Impact of COVID-19 on the mental health of surgeons and coping strategies. Head Neck 2020, 42, 1638-1644. [CrossRef]

72. Wang, X.; Cheng, Z. Cross-sectional studies: Strengths, weaknesses, and recommendations. Chest 2020, 158, S65-S71. [CrossRef]

73. Levin, J. Mental Health Care for Survivors and Healthcare Workers in the Aftermath of an Outbreak. In Psychiatry of Pandemics; Springer: Cham, Switzerland, 2019; pp. 127-141.

74. Althubaiti, A. Information bias in health research: Definition, pitfalls, and adjustment methods. J. Multidiscip. Healthc. 2016, 9 , 211. [CrossRef]

75. Rosenman, R.; Tennekoon, V.; Hill, L.G. Measuring bias in self-reported data. Int. J. Behav. Healthc. Res. 2011, 2, 320-332. [CrossRef]

76. Caughey, D.; Berinsky, A.J.; Chatfield, S.; Hartman, E.; Schickler, E.; Sekhon, J.S. Target Estimation and Adjustment Weighting for Survey Nonresponse and Sampling Bias; Cambridge University Press: Cambridge, UK, 2020.

77. Valliant, R.; Dever, J.A. Survey Weights: A Step-by-Step Guide to Calculation; Stata Press: College Station, TX, USA, 2018.

78. Scriven, A.; Smith-Ferrier, S. The application of online surveys for workplace health research. J. R. Soc. Promot. Health 2003, 123, 95-101. [CrossRef]

79. Jager, J.; Putnick, D.L.; Bornstein, M.H.I.I. More than just convenient: The scientific merits of homogeneous convenience samples. Monogr. Soc. Res. Child Dev. 2017, 82, 13-30. [CrossRef]

80. Bornstein, M.H.; Jager, J.; Putnick, D.L. Sampling in developmental science: Situations, shortcomings, solutions, and standards. Dev. Rev. 2013, 33, 357-370. [CrossRef] [PubMed]

81. Holmes, M.R.; Rentrope, C.R.; Korsch-Williams, A.; King, J.A. Impact of COVID-19 Pandemic on Posttraumatic Stress, Grief, Burnout, and Secondary Trauma of Social Workers in the United States. Clin. Soc. Work. J. 2021, 49, 495-504. [CrossRef] [PubMed]

82. Greenberg, N.; Docherty, M.; Gnanapragasam, S.; Wessely, S. Managing mental health challenges faced by healthcare workers during COVID-19 pandemic. BMJ 2020, 26, 368. [CrossRef] [PubMed]

83. Savaya, R.; Levin, L.; Roziner, I. Social workers in Israel: Daily stressors, work benefits, burnout and well-being. Br. J. Soc. Work 2021, 51, 318-339. [CrossRef]

84. Schieman, S.; Badawy, P.J.; Milkie, A.M.; Bierman, A. Work-life conflict during the COVID-19 pandemic. Socius 2021, 7, 2378023120982856. [CrossRef]

85. Marques, V.C.; Berry, G.R. Enhancing work-life balance using a resilience framework. Bus. Soc. Rev. 2021, 126, 263-281. [CrossRef] 